\title{
A new era for the journal Psicologia: Reflexão e Critica
}

\author{
Eduardo Remor
}

As new Editor-In-Chief I want to welcome you to the new era of the journal Psicologia: Reflexão e Crítica, from now on also known as Psychology: Research and Review. We have made important changes over the last years culminating with our move to publishing exclusively online with SpringerOpen, a Springer's new suite of open access journals. The journal continues its trajectory as open access since it was stablished in 1986 by professors from the Universidade Federal do Rio Grande do Sul - UFRGS/Brazil (Gomes and Fradkin 2015).

In launching this new era of the journal, it is timely to acknowledge distinguished scholars such as William B. Gomes, Silvia H. Koller, Cleonice A. Bosa, Lisiane A. Bizarro, Denise R. Bandeira, and Débora D. Dell'Aglio for their commitment to Psicologia: Reflexão e Crítica as past editors. Their past work has been crucial to lead the journal to the current point.

Springer, a world leading publisher in health and social sciences, has wisely identified Psicologia: Reflexão e Crítica as a leading journal in the region and decided to work with us to consolidate our path of internationalization process and bring more visibility to our journal abroad.

A publishing agreement was executed with Springer, starting with Volume 29, 2016 for a period of 10 years. Under this agreement the Programa de Pós-graduação em Psicologia at Universidade Federal do Rio Grande do $\mathrm{Sul}$ remains the owner of the periodical, and through the editors, will continue to exercise sole control of the editorial development and editorial content of the journal. Springer will be responsible for publishing the journal, including the entire costs of manufacturing, distribution, promotion and advertising. Springer supports the notion that scientific knowledge should be accessed by all and have subsequently maintained an online open access format, just as we used to operate. This means that the end users will be able to read and incorporate the research findings into their work and practice, helping to narrow

Correspondence: eduardo.remor@ufrgs.br

Institute of Psychology, Universidade Federal do Rio Grande do Sul, Porto Alegre, Brazil

(C) 2016 Remor. Open Access This article is distributed under the terms of the Creative Commons Attribution 4.0 International License (http://creativecommons.org/licenses/by/4.0/), which permits unrestricted use, distribution, and reproduction in any medium, provided you give appropriate credit to the original author(s) and the source, provide a link to the Creative Commons license, and indicate if changes were made. the gap between academic knowledge and practice. This connection between researchers and practitioners is very valuable in order to improve a more evidence-based training and practice in the fields of Psychology, which is particularly need in our region.

Despite of no cost being charged to the Programa de Pós-graduação em Psicologia, authors will pay an Article-Processing Charge (APC) for each article accepted for publication in the journal. However, in order to avoid that the lack of funds is an obstacle to publication, Springer has set different mechanisms to help APC be affordable to authors (i.e. waivers, discounts, free APC for Low-income economies, etc.). Moreover, authors based in Latin America will always benefit from a reduced APC. The reader will find detailed information about this matter in the journal's website (http:// www.prc.springeropen.com/, see APC FAQ section). The payment of APC grants the authors immediate worldwide open access to their full-text articles also distribution in various formats of online publication, inclusion in bibliographic databases and SpringerLink, inclusion in CrossRef enabling electronic citation in other journals available electronically and lifelong deposit in digital archives including e-Depot (The Netherlands).

Through this new beginning we renew our mission as an international peer-reviewed open access journal that publishes high-quality papers, describing empirical research and literature reviews on themes under four main fields of Psychology: Developmental Psychology, Psychological Processes/Experimental Psychology, Psychological Assessment and Health Psychology.

We expect that the material published in our journal continues contributing to the innovation and construction of theory and technology in Psychology, as well as to discussion on the current theoretical thinking, methodological issues, and scientific policy.

Psicologia: Reflexão e Crítica became a singular periodical, and a model in our context of pioneering initiatives towards internationalization. We would like to take

\section{Springer}


this opportunity to report and summarize the earlier mentioned journal's change process and achievements.

For example, it is worth to be mentioned the adoption of a call for Associate Editors selection, opening doors for extramural collaboration. This initiative was proposed and lead by the current Editor-in-Chief, and began in 2014 with the periodical selection process for the section of Psychological Assessment. On this occasion, 16 applications were received from outstanding researchers (Brazil and abroad) interested in participating in the board of editors, among which we selected three. Because the journal's growth in 2015, a call for all sections of the journal was opened again, when 28 candidates applied out of which 13 were foreigners. Seven new associate editors were selected on this occasion. Currently we have a team of 12 associate editors, divided in the four sections of the journal. They are motivated and compromised with the ambitious goals of the journal, and will treat each submitted manuscript with attention, care, respect and ethics through the editorial process.

Furthermore, four of the associate editors are currently linked to foreign institutions of Chile, Portugal and Spain, and among the Brazilian associate editors, these represent public and private universities in all regions of the country. The editorial board has been renewed as well, which now comprises a select group of 22 researchers ( $40 \%$ foreigners), all compromised with the journal goals. And among the 171 ad hoc consultations in 2015, approximately $20 \%$ were linked to foreign institutions.

Psicologia: Reflexão e Crítica is reaching out unprecedented internationalization shares among the Brazilian Psychology journals. The content of the journal is reaching far beyond students, teachers and researchers from the field of Psychology. The attention given to the journal in the scientific community is substantially growing along with potential to reach public in related areas such as Humanities, Social and Health Sciences.

Our journal, as other journals, has been evaluated by external indexes. Our capacity to disseminate knowledge and obtain citations is used as proxy for the relative importance of a journal within its field. This objective metrics is known as Impact Factor. Although this quantitative assessment method is not free of criticism, its use for making decisions in academic and science settings has increased (Hicks et al. 2015). Recently, researchers have manifested the need of a more comprehensive and integrative approach when assessing scientific and research performance and outcomes.

Therefore, in order to present a more comprehensive picture of the journal's performance in metrics, it is worth mentioning that it was the first Psychology journal in Brazil to be included in the Thomson-Reuters database (Web of Science ${ }^{\mathrm{Tm}}$ ). Its insertion took place in 2009, and, likewise in 2014 the retrospective impact factor for the last 5 years (Journal Citation Reports ${ }^{\bullet}$ of 5 -Year Impact Factor) has been 0.204. (Quartile 4). Similarly, the Scopus impact factor of the journal was 0.240 (Quartile 3 ), a stable value in recent years due to the high number of articles published annually. According to Scopus, the journal has the $\mathrm{H}$-index $=11$, the highest among the Brazilian and Latin-American journals, tied with Universitas Psychologica (Colombia). The percentage of international cooperation in articles published by Psicologia: Reflexão e Crítica was $50 \%$ in 2015. It is among the three Latin American journals with the highest number of citations received in the last 3 years. From now on, SpringerOpen will work closely with Thomson Reuters (ISI) to ensure that citation analysis of articles published in Psicologia: Reflexão e Crítica will be correctly available.

According to Gamba et al. (2015), the majority of citations received by Brazilian based Psychology journals come from Brazil and other Portuguese or Spanishspeaking countries. However, they predict that this trend tends to change as the prominent language shifts from Portuguese to English. In the next years we will have the opportunity to evaluate if this statement is valid for Psicologia: Reflexão e Crítica.

Likewise, Van Noorden (2014) suggests that research papers in Latin America still struggle to attract citations from the rest of the world. Although the author appoints the lack of indexation in major citation databases as one of the barriers, shall we say that there is no easy answer or solution to this problem.

Besides publishing exclusively in English, we believe that a number of important challenges needs to be overcome to achieve a higher percentage of readers and citations, and to consolidate the journal's position within the field of Psychology. For example, indexing in biomedical databases such as Medline is particularly important for the journal's dissemination and visibility. Another point is being able to attract submissions of high-quality papers, with well-designed research that presents novelty and cutting-edge findings, which will have more probability of citation.

In addition, and related to metrics, one of the features already included in the Springer's platform is Altmetric (http://www.altmetric.com/) which may help to follow the dissemination of the published material in social media and internet, allowing the journal and authors new sources of input and information coming from feedback from society and consumers.

In summary, in its $29^{\text {th }}$ years of existence, this journal has established itself as one of the most important means of publications in Psychology from Brazil and has been recognized by other countries and researchers abroad, especially with the increasing cooperation and interest of authors and international advisors. In 2015, from the total of 88 published articles in four regular 
issues, 44 were by Brazilian authors and the other half were authored or co-authored by authors in foreign institutions, representing $50 \%$ of the articles (35\% increase over the previous year). Out of the international authors, 86 were located in Portuguese institutions, 29 in Spain, five in the USA, three in Canada, three in Uruguay, two in the United Kingdom and two in Chile. The other five foreign authors belonged to institutions in France, Holland, Italy, New Zealand and Peru.

Considering all these achievements, we believe this is an exciting addition to the SpringerOpen portifolio of journals, once this is the first Psychology journal based in Latin America to be aggregate to SpringerOpen.

Finally, it is worth to remember that manuscripts submitted and published by Psicologia: Reflexão e Crítica will benefit from a convenient online submission platform (Editorial Manager ${ }^{\circ}$ ), rigorous peer review, immediate publication on acceptance, the article be freely available online (Open Access), high visibility within the field, retaining copyright of the article and information on article metrics.

We invite readers to access the web of the journal, read the new instructions for authors and submits your work and contributions you can make to help further advance the fields of Developmental Psychology, Psychological Processes/Experimental Psychology, Psychological Assessment and Health Psychology through the pages of Psicologia: Reflexão e Crítica!

\section{Acknowledgments}

This work is supported by the CNPq research grant (Bolsista de Produtividade em Pesquisa do CNPq - Nível 2) to the author and by a MCTI/ CNPq N24/2015 grant to Psicologia: Reflexão e Crítica (442852/2015-0).

Received: 15 January 2016 Accepted: 2 March 2016

Published online: 13 April 2016

\section{References}

Gamba EC, Packer AL, Meneghini R. Pathways to Internationalize Brazilian Journals of Psychology. Psicologia: Reflexão e Crítica. 2015;28 Suppl 1:66-71. https://dx.doi.org/10.1590/1678-7153.20152840010.

Gomes WB, Fradkin C. Editorial Psicologia: Reflexão e Crítica. 2015;28 Suppl 1:1. https://dx.doi.org/10.1590/1678-7153.2015284001.

Hicks D, Wouters P, Waltman L, Rijcke S, Rafols I. Bibliometrics: The Leiden Manifesto for research metrics. Nature. 2015;520:429-31. doi:10.1038/520429a.

Van Noorden R. The impact gap: South America by the numbers. Nature. 2014; 510:202-3. doi:10.1038/510202a.

\section{Submit your manuscript to a SpringerOpen ${ }^{\mathcal{O}}$ journal and benefit from:}

- Convenient online submission

- Rigorous peer review

- Immediate publication on acceptance

- Open access: articles freely available online

- High visibility within the field

- Retaining the copyright to your article

Submit your next manuscript at $\boldsymbol{s p r i n g e r o p e n . c o m ~}$ 